\title{
You never adapt alone - the role of Multi- Sectoral Partnerships in addressing urban climate risks
}

\author{
Swenja Surminski and Hayley Leck
}

March 2016

Centre for Climate Change Economics and Policy Working Paper No. 262

Grantham Research Institute on Climate Change and the Environment

Working Paper No. 232 
The Centre for Climate Change Economics and Policy (CCCEP) was established by the University of Leeds and the London School of Economics and Political Science in 2008 to advance public and private action on climate change through innovative, rigorous research. The Centre is funded by the UK Economic and Social Research Council. Its second phase started in 2013 and there are five integrated research themes:

1. Understanding green growth and climate-compatible development

2. Advancing climate finance and investment

3. Evaluating the performance of climate policies

4. Managing climate risks and uncertainties and strengthening climate services

5. Enabling rapid transitions in mitigation and adaptation

More information about the Centre for Climate Change Economics and Policy can be found at: http://www.cccep.ac.uk.

The Grantham Research Institute on Climate Change and the Environment was established by the London School of Economics and Political Science in 2008 to bring together international expertise on economics, finance, geography, the environment, international development and political economy to create a worldleading centre for policy-relevant research and training. The Institute is funded by the Grantham Foundation for the Protection of the Environment and the Global Green Growth Institute. It has nine research programmes:

1. Adaptation and development

2. Carbon trading and finance

3. Ecosystems, resources and the natural environment

4. Energy, technology and trade

5. Future generations and social justice

6. Growth and the economy

7. International environmental negotiations

8. Modelling and decision making

9. Private sector adaptation, risk and insurance

More information about the Grantham Research Institute on Climate Change and the Environment can be found at: http://www.Ise.ac.uk/grantham.

This working paper is intended to stimulate discussion within the research community and among users of research, and its content may have been submitted for publication in academic journals. It has been reviewed by at least one internal referee before publication. The views expressed in this paper represent those of the author(s) and do not necessarily represent those of the host institutions or funders. 


\title{
You never adapt alone - the role of Multi-Sectoral Partnerships in addressing urban climate risks
}

Swenja Surminski and Hayley Leck

\begin{abstract}
While multi-sectoral partnerships (MSPs) now form an increasingly popular and important part of the global climate and disaster risk governance landscape, particularly in urban areas, literature offers little critical investigation of this phenomenon. Through the lens of three partnership case studies from London, Rotterdam and Durban this paper investigates the scope for MSPs to enhance climate adaptation in an urban context. We investigate the drivers behind the formation of the MSPs and consider the concept of 'impact' that a MSP may have through surveys and interviews. We then consider the ability of a MSP to respond to changing needs and expectations- such as new scientific evidence, shifting policy directions and member priorities - which are key features of the adaptation and urban resilience fields. Our investigation supports our proposed distinction between 'first generation' and 'second generation' MSPs, reflecting on the dynamic nature of urban adaptation with a shifting focus from initial awareness raising and agenda setting towards the implementation of adaptation action. We notice that for long-established MSPs, such as the Durban and London examples, this shift can present several challenges, while it can also give rise to new, more targeted MSPs, as the example of Rotterdam shows.
\end{abstract}




\section{Introduction}

Climate risks cannot be addressed successfully at any single institutional or spatial scale or by any one category of actor. Measures to reduce and manage risk levels are determined at multiple scales and involve a broad range of stakeholders, including public and private sector actors. This has led to increasing attention towards the use of multi-scalar and multi-sectoral partnerships (MSPs) as mechanisms for engaging actors from various sectors with diverse perspectives and expertise to help tackle complex climate and broader environmental problems (Carmona et al., 2014; Máñez Costa, 2013). For example, the Hyogo Framework for Action, the UN's set of principles for disaster risk reduction, identified MSPs as critical and called for 'vigorous pursuit of MSPs' (UNISDR, 2011), while its successor agreement, the Sendai Framework, states that 'disaster risk reduction practices need to be multi-hazard and multispectral, inclusive and accessible in order to be efficient and effective' (UNISDR, 2015). The quest for more collaboration appears to have found particularly fertile ground at the urban level, as highlighted by Carmin et al. (2013) who present several examples of city based, stakeholder engagement partnerships aimed at adaptation to climate change in diverse contexts including large cities such as Toronto, Quito, London and smaller urban centres such as Walvis Bay in South Africa (Carmin et al., 2013, p. 24-25). This coincides with the realization that cities form a pivotal part in pursuing internationally agreed policy goals, including climate mitigation and adaptation, as well as disaster risk reduction and climate risk management (Bulkeley and Castán Broto, 2013). As Parnell (2016: 529) explains, the United Nation's recent approval of a stand-alone urban Sustainable Development Goal "marks a watershed in global development discourse on cities". Cities are of importance in managing climate risks as they serve as centres of economic activity, technology and innovation hubs, while often being exposed to a range of climate risks, including potential infrastructure failure, urban blight and loss to both populations and assets.

However, while MSPs now form an increasingly popular and important part of the global climate and disaster risk governance landscape, particularly in urban areas, we identify a clear gap in our analytical understanding of this phenomenon. Literature 
offers little critical investigation of climate-focused MSPs for influencing adaptation at various scales and the key opportunities and challenges thereto. Important aspects such as responsibilities and roles within these climate partnerships, motivation and interaction of members, as well as overall accountability and delivery of outputs are often far from clear. (Harman et al., 2015).

Through the lens of three partnership case studies from London, Rotterdam and Durban our paper addresses this analytical shortfall and proposes new theoretical and practical insights relevant to MSPs. The three cities are all members of the global network of leading cities known as the C40 City Climate Leadership Group as well as 100 Resilient Cities, and have all publicly identified climate risks as a current and future challenge and aim to drive action to minimise the impacts of a changing climate. This suggests a degree of institutionalization of adaptation and resilience in all three cities. However, we specifically chose three very different cases of MSPs to illustrate the variations in multi-sectoral collaboration within an urban context: The London Climate Change Partnership (LCCP) example showcases a long-running partnership, focused on knowledge-sharing and awareness raising between public and private actors at city level, as well as supporting activities on single issues, such as surface water flooding, involving city and local level actors. The Durban Climate Change Partnership (DCCP) exemplifies collaboration initially driven in large part by community stakeholders, with a strong emphasis on community participation, with the Durban Industry Climate Change Partnership DICCP recognising the importance of collaboration between public authorities and industry and facilitated by the City Administration. The Rotterdam Port example is the youngest initiative as it is very much a partnership under development, emerging in response to a particularly flood risk issue in the Port Area of Rotterdam, but without yet a fully formalized structure and membership.

Through these three examples we investigate the scope for MSPs to enhance climate adaptation in an urban context from two main angles: First, we consider if and how a MSP meets its aims, fulfils its function, and plays its role. One approach to assessing the role of partnerships is an investigation of their impact. We reflect on certain success metrics that have been proposed for understanding MSP impact such as its risk reduction role, vision towards achieving mutual benefits (sharing the same goals) and 
inclusion of different sectors (see for example Máñez Costa et al., 2013). In our view 'impacts' can occur at different levels, often intangible or invisible. More specifically, our findings highlight the complexities of identifying and demonstrating impact of partnerships in the climate risk and adaptation areas. Related to the 'impact' question is the specific function of a MSP within a dynamic policy field. This reflects on the progression of a policy area, such as adaptation, from early discussion stage, agenda setting to eventual delivery of measures, although we realise that in the case of climate adaptation this is a continuum rather than a single policy cycle.

Second, we explore how a partnership can adjust and respond to changing needs and expectations from within and outside the MSP- such as new scientific evidence, shifting policy directions and member priorities. This is particularly relevant for climate risks, where following an initial focus on awareness raising and knowledge sharing attention is increasingly shifting towards the practical implementation of policies and proposals. (Mimura et.al.2014). For MSPs this could require an adjustment of aim, membership and role description in order to respond to these changes. For example, a MSP launched to raise the profile of adaptation within the urban policy making community might have to revisit its role once an urban adaptation strategy has been developed and adopted. To investigate this further we propose a distinction between 'first generation' and 'second generation' MSPs in the urban adaptation and climate risk management context: 'First generation' MSPs are focused on the sharing of knowledge, awareness raising and lobbying for further action, while 'second generation' partnerships are aimed at finding solutions, methods and tools in addressing those climate risks. However, acknowledging the wide range of MSPs that continue to emerge we restrain from proposing a strict categorization, but rather aim at illustrating important features and aspects of these different MSPs. Broadly, our investigation goes to the heart of a growing adaptation policy discourse: who can adapt and how, what support functions exist, and how this relates to the adaptation cycle at multiple contexts.

\section{Partnership - a policy instrument, a form of governance or just the opposite of 'going it alone'?}


MSPs exist in many forms with a variety of different purposes and organisational structures, varied spatial and temporal scope, activities and governance arrangements, thereby making a typology challenging (Bauer and Steurer, 2014; Biermann et al., 2007; Glasbergen, 2007). In most simple terms MSPs are partnerships involving a mix of partners from the public and private sectors and civil society organisations. The word 'partnership' is often used interchangeably with co-operation, collaboration, network or alliance (Armistead et al., 2007). A range of categorisations have been proposed in the literature - such as public-private partnerships (PPPs), public-public partnerships (PuPs), as well as MSPs - mainly based on the composition of such partnerships. Beyond this there are differences in terms of the underlying structure and degree of formality: partnerships that are contractual based, delivering a particular public service, through to informal discussion forums. We understand MSPs as 'voluntary but enforceable commitments between partners from different sectors (public authorities, private services/enterprise and civil society), which can be temporary or long-lasting. They are based on the common goals of gaining mutual benefit, reducing current and future climate risk and increasing climate resilience'. (Manez et .al. 2013, p6) This definition of partnerships has been applied to the context of disaster risk management and climate adaptation, when investigating the role of MSPs in driving resilience (e.g. for example Manez.et.al 2013).

Since the mid-1990s there has been a proliferation of partnerships between public authorities, business and civil society actors focused on sustainability and environmental governance, with the idea of partnerships becoming a normative goal in environmental policy (McAllister and Taylor, 2015; Schaaf, 2015). The 2002 World Summit on Sustainable Development (WSSD) was a landmark for establishing the role of so called 'Type II partnerships' (between public and private actors) in delivering sustainability (Biermann et al., 2007). This was significant for the environmental arena as it epitomized the argument that responsibilities for governing global issues should be shared between public and private actors across all scales and governance levels (Bulkeley and Newell, 2010). 
Importantly, the emergence of these partnership approaches has not taken place in a political, economic or social vacuum. Trends in globalisation, neo-liberalism and political ideologies have been central to the means and rationale for their development (Bulkeley and Newell, 2010; McAllister and Taylor; 2015). The formation of partnerships have been directly supported through inter-institutional and cross- border co-operation and indirectly encouraged through a growing culture of consultation and dialogue (for the EU see ENHANCE D6.1: Mysiak et al., 2014), particularly at the municipal or local authority level. However, as Harman et al. $(2015$, p.74) contend: "there is little evidence of the value of these policy instruments to manage complex problems such as climate change in urban development contexts".

A key underpinning motive for partnership formation is the (perceived or otherwise) added value of working jointly rather than individually. Partnerships typically embrace common objective(s) and are predicated on a sense of co-operation, mutual trust and synergy (Schaaf, 2015; Vasconcellos and Vasconcellos, 2009), as well as (the voluntary nature of) commitments and emphasis on social benefits (McQuaid, 2000). Since multiple forms of loose collaboration or ad hoc arrangements can fulfil these principles, we add a formal institutional agreement as a discriminating component of a partnership for this study. Brinkerhoff et al. (2002) identify mutuality and organisation identity as two key features for defining partnerships and distinguishing them from other forms of relationships. Mutuality refers to mutual interdependence and relates to partnership principles such as horizontal co-ordination and accountability, equality in decision making and mutual trust. Importantly, according to Brinkerhoff et al. (2002) mutuality does not necessarily imply equal power relations but does seek to emphasise the criticality of each partner to encourage equality in decision-making. Organisation identity can be understood as that which is "distinctive and enduring in a particular organization" and "the key is not necessarily to maintain organization systems, processes and strategies over time, but to maintain the organisations core values and constituencies" (Brinkerhoff et al., 2002, p. 217).

Despite much research interest in recent decades, debates about the desirability and effectiveness of partnerships remain inconclusive. MSPs and other forms of collaboration hold the potential for innovative solutions but also raise considerable 
challenges in terms of power relations, equity and effectiveness (Bulkeley and Newell, 2010). Their growing popularity notwithstanding, not all partnerships are successful and have been subject to critique around several key themes such as accountability, stakeholder involvement, inclusivity, legality and transparency. Further, evaluations of partnership effectiveness or performance are often contradictory and inconsistent (McAllister and Taylor, 2015). Biermann et al. (2007) explain that partnerships are not a panacea for all sustainability related governance challenges, and question whether general conclusions about partnership effectiveness can be outlined at all, especially in light of the diversity of arrangements in this field.

Climate change is one particular area where we witness increasing emphasis on collaboration and communication between multiple actors to support the development of solutions and plans. Cities in particular have become key arenas for the formation and implementation of climate change partnerships, with collaborative partnerships for supporting climate mitigation, adaptation and disaster resilience implemented in many cities across the globe (Tanner et al, 2008; Carmin et al, 2013; Harman et al, 2015). These have often been supported by numerous regional and international networks such as the C40 City Climate Leadership Group, Cities and Climate Change Initiative (CCCI) and ICLEI - Local Governments for Sustainability. While focused on facilitating knowledge exchange, best practice and collaboration across the member cities, all of these initiatives highlight the importance of multi-sectoral engagement and buy-in across different stakeholders at local and city level for any progress in this area. (see for example UNISDR's resilient cities toolkit (UNISDR, 2016) The urban scale thus provides an interesting testing ground for the implementation of MSPs.

\section{The rise of climate change partnerships in urban contexts - the examples of London, Port of Rotterdam and Durban}

Large cities such as London, Rotterdam and Durban face complex cross boundary environmental and climate risks, which require collaborative management across spatial, political and organisational boundaries since they cannot be adequately dealt with solely by just one category of actor (Leck and Simon, 2013; Bulkeley and Newell; 2009). Durban is the second largest city in South Africa, with a population of 
approximately 3, 5 million (UN, 2011). Key climate risks to Durban include drought, flooding, both tidal and pluvial, heat waves and rising sea level and coastal erosion (Rockefeller, 2015a). Rotterdam is the second largest city in the Netherlands with a municipal population of 616,294 (Statistics Netherlands, 2013). It is a major port area and as such is at risk from flooding, both tidal and pluvial, as well as heat waves and drought (Rockefeller, 2015b). London is the most populous city of all three at 8,416,500 (Nomis, 2015) and climate risks include flooding, summer overheating and drought (Climate UK, 2012). All three cities have established climate MSPs to address the growing challenges of climate change.

Our evidence base has been developed over several years, with very close interactions with the London and Durban cases. Due to its nascent character the Rotterdam Port case is a much more exploratory example. Across the cases our insights are gained from official reports and publications, enhanced by interviews with those those directly involved in the MSP - or in the case of Rotterdam Port - in the early development efforts of the initiative. For Durban insights were mainly gained through in-depth meetings and discussions with key municipal stakeholders and environmental consultants of varying levels of seniority as part of on-going research on the city's climate change adaptation agenda between January 2009 and August 2015, while for the LCCP our investigations coincided with an initiative undertaken within the MSP to identify future strategy and focus. This enabled us to conduct a survey of LCCP members, completed at the end of October 2014. The Qualtrics web-based survey achieved a response rate of just over $85 \%$. The survey included closed and open-ended questions relating to multiple issues such as understanding of climate risks, sources of information, actions being undertaken by the LCCP and more specific questions such as current flood risk management in London. The survey was open for approximately three months and closed at the end of October 2014. The survey results were complemented by a focus group discussion meeting with LCCP members held in November 2014(attended by over 15 members), as well as several informal interviews with LCCP members and management representatives held between March and November 2014. These data sources were cross-referenced further with survey results from internal LCCP research conducted in 2012 which elicited LCCP members' perceptions on successes, aims and own achievements. Furthermore, we assessed key 
notes from an internal brainstorming session, held in 2012, which fed into the LCCP 2020 vision. Similar to the work in Durban we also conducted interviews and participated in meetings as well as a roundtable discussion with members on the survey results in November 2014. For the case of Rotterdam Port the evidence base is still very limited as the MSP is still in it's formative stages. During the formative period of this MSP from 2014 - 2015 we gained our insights through in-depth discussions with those flood risk experts who are supporting and facilitating the development of this new MSP, as well as through assessment of statements and commentaries from the prospective members of this partnership.

\subsection{The London Climate Change Partnership (LCCP)}

In London, the LCCP's approach has focussed on harnessing the understanding and expertise of local, national and city-level specific organisations and representatives, including a range of public and private bodies. This strategy has facilitated the delivery of advice, research and understanding of how London can become a climate resilient city. While launched by the then London mayor Ken Livingstone in 2001, the LCCP needs to be seen in the context of a wider wave of MSP creation in the UK. MSPs are well established in the UK and have been promoted by the government since the mid 1980s with an emphasis on local governments partnering with corporate actors such as industry and other stakeholders to achieve key objectives (Keskitalo, 2010). Established in 1997, the UK Climate Impacts Programme (UKCIP) is a major government funded organisation based at Oxford University (UKCIP, 2015). In addition to developing decision support tools and other functions, UKCIP has been central to the development of the Regional Climate Change Partnership (RCCP), now called Climate UK. Climate UK is a not-for-profit Community Interest Company and a national network of twelve climate change partnerships in England, Northern Ireland, Scotland and Wales. The main objectives of this umbrella group are to investigate, advise and inform on potential risks and opportunities posed by climate change; and coordinate and support integrated and sustainable responses, thus playing an important role in the development of the UK climate change adaptation agenda. UKCIP has also previously provided a platform for the development of the informal UK Interregional Climate Change Group (UKIRCCG) which represents climate change partnerships across all UK regions. The LCCP is a pertinent example of a long-running effort to bring together 
public and private sector players within an urban context. The partnership has a longterm outlook and supports climate risk reduction and climate change adaptation across London. Coordination and facilitation of the LCCP is government led, with funding from the environment programme budget from the Greater London Authority (GLA), the city government for London. There are 23 members (as of May 2014). Workstreams involve assessment of, and research in to specific climate risks as well as action on resilience. Functioning alongside and in collaboration with the LCCP are the 33 London boroughs (local government) and other knowledge networks. These include additional projects for climate resilience, such as Drain London; a cross boundary strategy to develop surface water management plans for London and its boroughs. Regarding the proposed generational framing, the LCCP finds it origins in the first generation category and over time and through specific initiatives such as Drain London has evolved to the 'second generation' categorisation.

\subsection{The Port of Rotterdam case}

The example from Rotterdam explores the creation of a new MSP focused on flood risk management in the outer dyke areas of the Port Area of Rotterdam and can be classified as a 'second generation' MSP from the outset. It is emerging under the broad umbrella of the Rotterdam Climate Initiative, a city-wide climate change partnership founded in May 2007, with the objective of reducing CO2 emissions by $50 \%$ and climate proofing the city. It is a broad partnership between the City of Rotterdam, the Port of Rotterdam, DCMR Environmental Protection Agency Rijnmond, and Deltalinqs. The outer dyke flood risk challenge was acknowledged in Rotterdam's Adaptation Strategy (Rotterdam Climate Initiative, 2015)as an issue requiring collaboration between different layers of authorities and various stakeholders, including individual businesses operating in the port, the Port of Rotterdam Authority, the national Ministerie van Infrastructuur en Milieu, the provincial adminstrators in Provincie Zuid-Holland, and municipal actors.. Furthermore, the national government's Delta Programme identified clear knowledge and governance gaps: flood risk levels in the outdyke areas were unknown, while there was also no clear responsibility in terms of protecting anyone based or operating in these areas. (Nicoli et al, 2015; Nicoli et al, 2014) The new MSP is aiming to promote new flood risk responses, such as insurance or business continuity measures, through greater participation and engagement of the different stakeholders. The willingness of 
stakeholders to collaborate has been linked to the publication of new risk data and new modelling analysis, highlighting the scale of flood risk as well as current and future socio-economic impacts (Nicoli et al, 2015; Nicoli et al, 2014).

\section{$\underline{3.3 \text { The Durban Climate Change Partnership and Durban Industry Climate Change }}$}

\section{Partnership}

The city of Durban as an example of South Africa's recent experience of creating and implementing a climate change partnership reveals important insights into the challenges and opportunities that exist in such an approach. Durban was the first city in South Africa to accept the Local Agenda $21^{1}$ (LA21) mandate as a corporate responsibility and is a forerunner of the country's LA21 movement. Durban local government recognised the centrality of multi-stakeholder partnerships for advancing the LA21 from early on (Roberts and Diederichs, 2002). Durban is also considered a leader in developing contexts in terms of their early and proactive approach to tackling climate change, with a strong emphasis on adaptation (Roberts and Leck, 2015).

Central to Durban's evolving climate agenda is the recognition of the importance of cooperation between a large numbers of diverse stakeholders. The municipality received a mandate to develop a 'Durban Climate Change Partnership' (DCCP) at the Durban Climate Change Summit held in May 2009, thus signifying a pivotal moment for the city's climate partnership agenda. This broadly representative partnership was intended to bring together diverse stakeholders including public, private and civil society actors in a structured, open and inclusive manner to tackle both adaptation and mitigation issues (Roberts, 2010), and to open up significant opportunities for advancing the city's climate agenda and for supporting and strengthening resilience. The DCCP was initiated through a democratic process that involved public consultations and the establishment of an advisory forum to elect a steering committee, rather than through the mayor, as seen with LCCP and similar partnerships elsewhere. However, , champion figures from the local government, non-government organizations and

\footnotetext{
${ }^{1}$ The Local Agenda 21 stems from agreement at the Rio Earth Summit (UN Conference on Environment and Development) in 1992, that sustainable development action should be driven at not only the national and global levels but also the local level.
} 
general public have played a major part in attempting to sustain the partnership (Interview, 23 July 2014). In addition to and alongside the DCCP the Durban Industry Climate Change Partnership (DICCP) was formed in June 2009 when the eThekwini Municipality signed a partnership declaration with local and national business leadership in conjunction with UNIDO to promote climate change mitigation and adaptation. Other partners are the Durban Investment Promotion Agency (DIPA) and the Durban Chamber of Commerce (Aylett, 2010). The DICCP is a strategic cross-sector partnership with the core aim to foster sector specific collaborations within the city and provide support to eThekwini Municipality's Energy Office to promote implementation of the formally adopted Municipal Energy Strategy in addition to meeting emissions reduction targets (Aylett, 2010). The DICCP also hosted a number of climate change response workshops with a variety of economic clusters during 2010. The partnership officially ran from June 2009 to June 2010 with the intention of creating a subsequent "sustained partnership of the industrial and public sector in Durban to effectively contribute towards climate change mitigation and adaptation" (UNIDO, 2009, p.1). While the DCPP originated as a 'first generation' partnership, the DICCP originated more on the boundary of the first and second generation classification.

Durban's partnership ethos has recently been strengthened further by the Durban Adaptation Charter (DAC) for Local Governments which was adopted on $4^{\text {th }}$ December 2011 at COP 15 and places a strong emphasis on partnerships through clauses 9 and 10 as follows: "(9) Promote multi-level and integrated governance and advocate for partnerships with sub-national and national governments on local climate action and (10) Promote partnerships at all levels and city-to-city co-operation and knowledge exchange" (DAC, 2011, p.6).

\section{Investigating the role of urban MSPs - findings from the three cases}

Through the lens of our three case studies we can consider several key features of partnership approaches for addressing climate risks in an urban context. We start by exploring the drivers behind the formation of the MSPs, with a particular focus on members' views with regards to the functioning of their partnership, covering perceptions, motivations and expectations (4.1). We then consider if and how one can 
derive at an understanding of 'impact' of a MSP in terms of managing climate risks. (4.2) As alluded to earlier, understanding and assessing the MSPs' impact is particularly complex and has been widely debated (Biermann et al., 2007; McAllister and Taylor; 2015). One way of doing this is to consider official descriptions of MSP roles and set-up, then assess if and how this has been achieved. Our survey and discussions with LCCP members as well as the analysis of the Durban initiatives offer such an investigation. For the Port of Rotterdam the formal MSP is still under development, but there is evidence of the pulling power of risk information and new analysis, which is bringing together the different sectors in search for a solution to this one particular flood risk issue. Finally we consider in greater detail the three cases in relation to the proposed first and second generation MSP classification and what this implies for a city's ability to respond to the dynamics of climate adaptation. (4.3)

4.1 What drives a MSP? A reflection on external and internal factors, with a focus on perceptions, motivations and expectations of MSP members

As outlined above, MSPs are influenced by a wide range of internal and external factors. Each of the city case studies demonstrate that the creation and momentum of MSPs are frequently driven by the efforts of individual leaders or 'champions' who often bring in pre-existing contacts and networks (Wohlsetter et al., 2005). As a Durban official explained with reference to the DICCP, "it has been good for us to use partnerships as vehicles to pull champions together and to identify spaces that can we slot the champions into. Without institutional champions it just doesn't work...but they are still the minority" (Interview, 23 July 2014). The DICCP's strategy also focused on harnessing the experiences and expertise of 'efficiency leaders' in each sector to facilitate mainstreaming of efficiency and mitigation measures (Aylett, 2010). Despite its institutional/organisational based membership much of the LCCP's activities and momentum are driven by key individuals, many of whom have been involved with the LCCP since its early formation (Interview, 11 September 2014). Despite their apparent centrality to MSPs, there are potential pitfalls to relying heavily on champions since should they move on from the partnership a considerable void is likely to be left and the longevity of the MSP brought into question (Leck and Roberts, 2015). 
Members of a partnership may have very different motives and motivations when joining a MSP, while their perceptions of the role and relevance of the MSP can also vary (Armistead, 2007). The LCCP members identify 'information and knowledge sharing' as their main motivation for joining LCCP (listed by $89 \%$ of LCCP members), followed by interest in supporting climate adaptation and resilience in London (84\%) and influencing climate change and policy (84\%). Conducting research and developing solutions towards climate adaptation and resilience is also valued as a strong reason to join (52\%). Accordingly most members also see the function of their partnership predominantly in the context of awareness raising and capacity building: information dissemination and establishing a knowledge network were identified by $95 \%$ of the members as functions of LCCP, followed by 'knowledge exchange' (89\%) and 'lobbying for adaptation in London' (84\%).

Improved awareness, communication, collaboration and governance are key underpinning motives for the formation of our MSP case studies and are also subsequently core expectations from members. According to those involved in the current development of a new MSP for the Port of Rotterdam there are two key factors driving this new collaboration: first a broad recognition of a governance gap for flood risk in the outer dyke areas (Nicoli et.al. 2014): "Although located on relatively high grounds, the port is located outside of the primary flood defence system of the Netherlands. These areas are therefore classified as outer dike or unembanked regions and are not incorporated in the national flood protection policy. This means that land owners and business in these regions are responsible for their own flood protection" (Nicoli et.al. 2015). A 2009 survey amongst land owners and local municipalities showed that the application of existing outer dike policy is not always clear and consistent (Nicoli et al., 2014). Second, a key pull for multi-sectoral collaboration is arising through new risk models highlighting significant "consequential financial damages to the Netherlands as a result of a long-term disruption to the services in the Port of Rotterdam" (Nicoli et al., 2014). This has now become a key focus of the new MSP, triggering the collaboration in search for new solutions.

Our discussion with MSP members also revealed that the longevity and organizational stability of a partnership can be interpreted as an indicator for the value that members seem to derive from their membership. In London a third of all LCCP members have 
been involved in the LCCP for 6-10 years. In contrast, the DCCP's longevity was undermined by several interlinked factors; predominantly distrust between stakeholder groups from early on, weak long- term commitments from participants and lack of funding. As such, Durban's experience exemplifies the centrality of trust for supporting MSPs. For the Rotterdam example it is also apparent that trust is a key factor determining if a partnership can move beyond an informal knowledge exchange to a relevant stakeholder in managing flood risk in the Port area.

\section{$\underline{4.2 \text { Impact and effectiveness }}$}

Assessing the impact and effectiveness of MSPs is challenging and we face a very limited evidence base when analysing if and how partnerships can manage complex problems such as climate risks in urban development contexts (Harman et al., 2015). One key challenge is the diverging view of what impact means. Members' opinions on the impact of LCCP in London show the difficulty and sometimes conflicting viewpoint in capturing this: A small number of respondents (5\%) indicate that the partnership had no impact on adaptation in London, while $47 \%$ remain unsure and $47 \%$ see definite impact on adaptation. Of those, $89 \%$ see an impact through the information and guidance on adaptation provided through LCCP, as well as through the facilitator role of LCCP, helping to drive forward climate adaptation and resilience (89\%) both ranked as the most common impacts that the LCCP have on adaptation in London. This is followed by informing climate change adaptation policy (77\%), raising awareness of the impacts of climate change within own organisations and individuals (67\%) and monitoring preparedness of London to climate change (44\%).

While the Rotterdam MSP is only in the process of being formed there are some indications that it has already had an impact on the approach to flood risk management in the Port Area. Since its inception, the Port Authority has officially committed to a pilot study in the Botlek Area in collaboration with the private sector and government bodies at national, regional and municipal level. For the pilot area several potential response measures and solutions are tested. These include measures such as elevation, infrastructure investments, stricter building codes and insurance. An important element is the 'stress testing' instruments developed to consider different types of floods as well 
as reflecting on different climate change scenarios. MSP partners consider this as a move towards a more strategic problem solving approach (Nicoli et al., 2014).

While the DCCP can account for specific results, such as an increased awareness and more knowledge sharing across diverse communities, it has also faced considerable challenges. While the DCCP can account for specific results, such as an increased awareness and more knowledge sharing across diverse communities, it has also faced considerable challenges. The steering committee has been considered largely ineffectual due to funding constraints, with the municipality's engagement with the partnership and steering committee moving towards 'observation' rather than active involvement. (Roberts and O’Donoghue, 2013).

Interviews and LCCP survey results reveal that most respondents from each of the three cases feel that it is difficult to measure impact, especially because the partnerships serve a wide variety of purposes with impacts often being cumulative and intangible. During the LCCP meeting partners explained several challenges to assessment and attribution of impact including the difficulties of demonstrating 'value added' and the difficulty of separating out LCCP's influence from other influential organisations and factors in the city and beyond. Similarly, a Durban official engaged in the DCCP explained that it is a "hazy and tricky business to show what difference has been made by the partnership's existence" (9 March 2015). These findings resonate with the broader literature on partnerships for environmental sustainability where the difficulties of measuring partnership impact have been highlighted in relation to the 'background noise' of other factors, such as related and co-existing partnership arrangements as well as government actions and the complexities of attributing changes in behaviour or policy to the influence of individual partnerships (Biermann et al., 2007).

\section{$\underline{4.3 \text { Dynamism and flexibility }}$}

MSP dynamism and flexibility are important prerequisites in urban contexts characterised by continuous and often rapid shifts in policy, planning and practice. It is thus important for climate change focused MSPs to identify the stage(s) of the evolving 
adaptation policy cycle that they target or relate to and how this might shift over time and the necessary prerequisites for undertaking such transitions.

The LCCP has been targeting London's evolving adaptation policy context. It_forms an integral component of the Mayor's strategy for building climate change resilience for London. During its initial stages the LCCP's work stream focussed strongly on research into specific climate risks, information sharing and awareness raising. As the partnership evolved its focus has shifted towards supporting the delivery of projects for climate resilience such as 'Drain London'; a cross boundary strategy to develop surface water management plans for London. This has been supported by the 33 London boroughs (local government) and other knowledge networks that function alongside and in collaboration with the LCCP. Partnership members see the LCCP's functions as diverse, spanning from awareness raising to adaptation implementation, enabling the partnership to respond to changing needs and demands. However, in times of fiscal austerity the public funding for the LCCP is under threat, leaving a question mark about its future contribution to adaptation in London (Interview, 9 March 2015).

The emerging Rotterdam MSP is focused on flood risk in the Port Area but its work might also have implications for other areas, including residential areas in Rotterdam and elsewhere. It is very much a single-issue MSP, however there are links to the wider adaptation agenda and potentially to wider networks and partnerships. The initial efforts focused on new risk information and modelling results, which is likely to be followed by an assessment of response mechanisms and solutions. The current pilot could lead to re-adjustment of development policies in outer-dyke areas and to increase awareness of flood risk of stakeholders in outer-dyke areas.

The DCCP example reveals considerable financial, capacity, and political restraints, impacting its dynamism and flexibility. The major hindering factor for partnership dynamism and longevity is a lack of access to financial resources after the initial period of funding from eThekwini Municipality expired. The executive committee is exploring new funding models, but in the interim the partnership is in hiatus (Interview, 23 July 2014). However, it is important to note that originally the DICCP was developed with a funded lifespan of one year with the intention of providing a basis for sustained momentum for ongoing partnering and collaboration between the industrial and public 
sector in Durban to effectively contribute towards climate change mitigation and adaptation (UNIDO, 2009). According to its members there is still a degree of collaboration between members despite this unclear status, however they widely blame, funding constraints, inadequate political will and lack of commitment from some sectors and partners as hampering the dynamism and momentum of the partnership beyond the initial first year period (Interviews, 15 October 2013).

\section{Discussion and conclusion}

Collaboration across sectors appears to be an important cornerstone for urban climate resilience due to the complexity and multi-faceted nature of current and future climate risks. This explains why the notion of MSPs has received so much backing from international networks such as 100 resilient cities, C40 City Climate Leadership Group and ICLEI. Common analysis of MSPs tends to apply an external lens with a focus on governance aspects, legal implications or the economic efficiency that may be derived from the collaborations (Krumm and Mause 2009). However, what is often overlooked are the personal characteristics and motivations of the members who form the central core in any MSP. The understanding of remit and function as well as the motivation to join can vary from member to member. These partners often pursue competing agendas outside an MSP but see value in participating and collaborating to achieve a common aim.For all three cases investigated it is clear that members join partnerships with different expectations and perceptions.

Our analysis confirms that MSPs already play a role in urban adaptation. However impact, success and effectiveness are hard to measure. These are highly normative questions, and in the absence of clear resilience measures or benchmarks for 'a well adapted city' an assessment of the contribution of MSPs remains subjective, as highlighted by the case of London. From a broader societal perspective the key question is if and how a MSP addresses the particular needs of a location, a problem or adaptation as such: raising awareness and contributing to a better understanding of risks and adaptation are important aspects particularly at the early stages of the adaptation policy cycle. 
Importantly MSPs are voluntary arrangements, and the buy-in from members, as well as their ability to contribute either financially or in kind, can change dramatically over the lifetime of such a partnership. Reflecting on changing needs and wants of members as well as the shifting landscape of adaptation policy and broader financial and political climates are important elements when trying to improve our understanding of role and reach of these MSPs. Urban adaptation is a continuous process, involving risk assessment, early awareness raising and capacity building, before considering the implementation of particular measures to address climate risk and increase resilience, which then needs monitoring and adjusting, subject to new risk assessment and appraisals.

Our investigation supports our proposed distinction between 'first generation' and 'second generation' MSPs, reflecting on this dynamic nature of urban adaptation. We notice a 'first generation' of urban climate risks partnerships, focused on sharing knowledge, raising awareness as well as lobbying for more action, as the MSPs in Durban and London show. As the climate risk policy area matures and the understanding of urban risks improve the notion of acting and implementing comes to the fore. This is highlighted by the LCCP's quest for new strategic outlook, raising the question of how to have impact beyond the initial information sharing function. This can lead to 'second' generation of partnerships - such as the Rotterdam Port case, which appears to take advantage of existing collaborative structures in the city, while focussing on specific topical solutions. A somewhat similar example would be the 'Drain London' network, that the LCCP initiated in response to the growing awareness of surface water flooding as a key threat to London, or, to a lesser extent, the creation of the DICCP in Durban. Moving beyond this initial stage towards implementation of adaptation action appears to require an adjustment in aim, membership and role description of the MSP. This may or may not be supported by all existing members, and could also lead to changes in membership, focus and overall structure. The LCCP is an interesting example where the partnership has been considerably effective at these early functions, including policy influence over the past ten years, but focus on adaptation implementation in line with the city's adaptation policy cycle has proven more challenging. 
Existing MSP members may see the implementation and execution of adaptation measures as an internal affair, happening within their own organisations, rather than driven by the partnership. Here the main role of the MSP is to provide the ground for member action - sharing information, data, facilitating knowledge exchange. This can be a fruitful process, where the MSP provides the stimulus, information and framework for an individual member to take action. However, it also means that the MSP has little direct influence over member action and relies on their continuous voluntary buy-in and support. As illustrated by Durban's two climate partnership examples, such actions are unlikely to be prioritised and sustained without further financial backing and investment by members. In other cases this may lead to the creation of new MSPs more single issue oriented and practical in outlook then the 'first generation' or urban climate MSPs, as seen in Rotterdam.

While MSPs have often been viewed as "the best way to deal with multifaceted problems in the current epoch" (Pinkse and Kolk, 2012), they should not be seen as panaceas and a solution to all problems within disaster risk management and climate adaptation. Critics have questioned the ability of partnerships to address the regulation, implementation and participation deficits in particular in situations where effective governments are lacking and where there are strong political divides between sectors (Forsyth, 2010). It is therefore clear that MSPs are unlikely to replace the more traditional approaches to governance. They can rather complement, and influence this process. Here the distinction between 'first' and 'second generation' MSPs appears to be of use: while agenda setting and information sharing appears to be a relatively simple form of engagement, this becomes more complex and possibly more controversial once the MSP is more targeted at the delivery and implementation of solutions. This can also raise questions over mandate and accountability. As our three cases have not (yet) assumed this implementation focused role it is too early to investigate the implications of this. However, it is clear that an initial focus on knowledge sharing and awareness raising covers what one could term the 'low hanging fruits' of collaboration, while 
implementing concrete measures such as investing in flood defences or building resilient infrastructure is likely to require a different set of members or rules of engagement as well as resources and capacities. This should not be interpreted as a limitation of MSPs for supporting urban adaptation, it simply signals the importance of clarifying where in the process of increasing urban resilience a city is and what type of collaboration is needed and considered feasible by those involved.

\section{Acknowledgements}

The authors would like to thank Robin Nikolai, the London Climate Change Partnership and Durban Climate Change Partnership / Durban Industry Climate Change Partnership and Jillian Eldrige for their insights and support. This paper has benefited from research undertaken as part of the ENHANCE Project (Enhancing risk management partnerships for catastrophic natural hazards in Europe), funded under the Seventh Framework Programme of the European Union under grant agreement No 308438. The authors would also like to acknowledge the financial support of the UK Economic and Social Research Council (ESRC) through the Centre for Climate Change Economics and Policy.

\section{References}

Armistead, C., Pettigrew, P., and Aves, S., 2007. Exploring leadership in multi-sectoral partnerships. Leadership, 3(2), pp. 211-230.

Aylett, A., 2010. Conflict, collaboration and climate change: participatory democracy and urban environmental struggles in Durban, South Africa. International Journal of Urban and Regional Research, 34(3), pp. 478-495.

Beisheim, M., and Liese, A. (Eds.). (2014). Transnational Partnerships: Effectively Providing for Sustainable Development?. London: Palgrave Macmillan.

Biermann, F., Chan, M., Mert, A. and Pattberg, P. 2007. Multi-stakeholder Partnerships for Sustainable Development: Does the Promise Hold? Glasbergen et al. (Eds.) In Partnerships, Governance and Sustainable Development. Reflections on Theory and Practice, Cheltenham, UK: Edward Elgar. pp. 239-60. 
Brinkerhoff, J. M., 2002. Assessing and improving partnership relationships and outcomes: a proposed framework. Evaluation and program planning, 25(3), pp. 215231.

Bulkeley, H. and Newell, P., 2010. Governing Climate Change. New York, USA: Routledge. Bulkeley, H. \& Castán Broto, V. (2013) Government by experiment? Global cities and the governing of climate change. Transactions of the Institute of British Geographers 38: 361375

Bauer, A., and Steurer, R., 2014. Innovation in climate adaptation policy: are regional partnerships catalysts or talking shops? Environmental Politics, 23(5), pp. 818-838.

Börzel, T. A., and Risse, T. (2005). Public-Private Partnerships: Effective and legitimate tools of international governance. Grande, E. and Pauly L. W. (Eds.) Complex Sovereignty: Reconstructing Political Authority in the Twenty First Century, pp. 195-216.

Carmona, M., Mañez, M., González-Riancho Calzada, P., Bayer, J., Hanger, S., Surminski, S., Haro, D., Andreu, J. and Mysiak, J. 2014. Deliverable 4.1: Inventory: Assessing risk perception criteria. ENHANCE Project Paper D4.1. European Commission. Available at: http://www.enhanceproject.eu/uploads/deliverable/file/18/ENHANCE D4.1 Workin g paper Risk perception and risk cultures in Europe.pdf [accessed 20 August 2015].

Carmin, J., D. Dodman and E. Chu. 2013. 'Urban Climate Adaptation and Leadership: From Conceptual Understanding to Practical Action', OECD Regional Development Working Papers, 2013/26, OECD Publishing. http://dx.doi.org/10.1787/5k3ttg88w8hhen.

Climate UK, 2012. A Summary of Climate Change Risks for London. Climate UK. Available at: http://climatelondon.org.uk/wp-content/uploads/2012/01/CCRALondon.pdf [accessed 17 June 2015].

DAC, 2011. Durban Adaptation Charter for Local Governments as adopted on the 4th December 2011 of the occasion of the "Durban Local Government Convention: adapting to a changing climate" - towards COP17/CMP7 and beyond -. The DAC Secretariat. Available at: http://durbanadaptationcharter.org/wp- 
content/uploads/2015/06/Durban Adaptation Charter 5 December 2011.pdf [accessed 26 August 2015].

ENHANCE (2012) Website of the EHNANCE Project. European Commission. Available at: http://enhanceproject.eu/ [accessed 26 August 2015].

Glasbergen, P., 2007. Setting the scene: the partnership paradigm in the making. Partnerships, governance and sustainable development: reflections on theory and practice, in Glasbergen, P., Biermann, F., and Mol, A. P. (Eds.). In Partnerships, governance and sustainable development: Reflections on theory and practice. Cheltenham, UK: Edward Elgar Publishing, pp.1-25.

Harman, B. P., Taylor, B. M. and Lane, M. 2015. Urban Partnerships and Climate Change Adaptation: Challenges and Opportunities. Current Opinion in Environmental Sustainability, 12, pp. 74-79.

Keskitalo, E. C 2010. Climate Change Adaptation in the United Kingdom: England and South-East England, Chapter 3 in Developing Adaptation Policy and Practice in Europe: Multi-level Governance of Climate Change (Keskitalo ed), London: Springer.

Krumm, T. and Mause, K. 2009. Public-Private Partnerships Gegenstand der (Politik) Wissenschaft Politische Vierteljahresschrift, March 2009, Volume 50, Issue 1, pp 105129

Leck, H and Roberts, D 2015. What lies beneath: understanding the invisible aspects of municipal climate change governance, Current Opinion in Environmental Sustainability, 13, pp. 61-67.

Máñez Costa, M., Carmona, M., Gee, K., Gerkensmeier, B., Ratter, B. M. W., Botzen, W., Aerts, J. and Paudel, Y., 2013. Deliverable 2.3 Governance Indicators for (Un)successful MSPs, ENHANCE Working Paper. European Commission. Available at:

http://enhanceproject.eu/uploads/deliverable/file/13/ENHANCE D2.3 Governance in dicators.pdf [accessed 26 August 2015]. 
McAllister, R. J., and Taylor. B. M., 2015. Partnerships for Sustainability Governance: A Synthesis of Key Themes. Current Opinion in Environmental Sustainability, 12, pp. 86-90.

McQuaid, R. W., 2000. The theory of partnerships - why have partnerships? In S. P. Osborne (ed.), Managing Public-Private Partnerships for Public Services: An International Perspective, London: Routledge, pp. 9-36.

Mimura, N., R.S. Pulwarty, D.M. Duc, I. Elshinnawy, M.H. Redsteer, H.Q. Huang, J.N. Nkem, and R.A. Sanchez Rodriguez, 2014:Adaptation planning and implementation. In: Climate Change 2014: Impacts, Adaptation, and Vulnerability. Part A: Global and Sectoral Aspects. Contribution of Working Group II to the Fifth Assessment Report of the Intergovernmental Panel on Climate Change [Field, C.B., V.R. Barros, D.J. Dokken, K.J. Mach, M.D. Mastrandrea, T.E. Bilir, M. Chatterjee, K.L. Ebi, Y.O. Estrada, R.C. Genova, B. Girma, E.S. Kissel, A.N. Levy, S. MacCracken, P.R. Mastrandrea, and L.L.White (eds.)]. Cambridge University Press, Cambridge, United Kingdom and New York, NY, USA, pp. 869-898.

Mysiak, J., Calliari, E. and Peréz Blanco, D., 2014. Deliverable 6.1: Inventory of Policy Instruments and Indicators for MSP-Policy Interaction. ENHANCE Project, European Commission. Available at:

http://enhanceproject.eu/uploads/deliverable/file/25/ENHANCE D6.1 Inventory of p olicy instruments and indicators for MSP-policy interactions.pdf [accessed 26 August 2015].

Nicoli, R., Pleijter, G., Huizinga, J., de Greef, J. and Vilier, J., 2015. Deliverable 7.3: Risk assessment results- Case study Port of Rotterdam infrastructure. ENHANCE Deliverable 7.3. European Commission, Brussels, Belgium.

Nicoli, R., Pleijter, G., de Greef, J. and van Vuren, S., 2014. Deliverable 7.2: Development of MSP - Case study Port of Rotterdam infrastructure. ENHANCE Deliverable 7.2. European Commission, Brussels, Belgium.

Nomis, 2015. London population as of 2013. Available at: https://www.nomisweb.co.uk/reports/lmp/gor/2013265927/report.aspx\#tabrespop [accessed 17 June 2015]. 
Parnell, S. 2016. Defining a Global Urban Development Agenda, World Development, 78 $529-540$

Roberts, D. and Diederichs, N., 2002. Durban's Local Agenda 21 programme: tackling sustainable development in a post-apartheid city, Environment \& Urbanization, 14(1), pp. 189-281.

Roberts, D., 2010. Prioritizing climate change adaptation and local level resilience in Durban, South Africa. Environment and Urbanization, 22(2), pp. 397-413.

Roberts, D. and O'Donoghue, 2013. Urban environmental challenges and climate change action in Durban, South Africa. Environment and Urbanization October, 25, pp. 299-319. Rockerfeller, 2015a. Durban's Resilience Challenge. Available at: http://www.100resilientcities.org/cities/entry/durbans-resilience-challenge\#/-_/ [accessed 17 June 2015].

Rockefeller, 2015b. Rotterdam's Resilience Challenge. Available at: http://www.100resilientcities.org/cities/entry/rotterdams-resilience-challenge\#/-_/ [accessed 17 June 2015].

Rotterdam Climate Initiative, 2015 . Rotterdam Climate Change Adaptation Strategy Available at: http://www.rotterdamclimateinitiative.nl/en/100procent-climateproof/projecten/rotterdam-climate-change-adaptationstrategy?portfolio id=181[accessed 25 August 2015].

Schaaf, R., 2015. The Rhetoric and Reality of Partnerships for International Development, Geography Compass, 9(2), pp. 68-80.

Statistics Netherlands, 2013. Population dynamics; birth, death and migration per region. Available at:

http://statline.cbs.nl/Statweb/publication/?DM=SLEN\&PA=37259eng\&D1=0-1,3,89,14,16,21-22,24\&D2=0\&D3=933\&D4=0,10,20,30,40,(1-1)-1\&LA=EN\&VW=C $[$ accessed 17 June 2015]. 
Tanner, T.M., Mitchell, T., Polack, E., and Guenther, B. 2008. Urban Governance for Adaptation: Assessing Climate Change Resilience in Ten Asian Cities. Report to Rockefeller Foundation, Institute of Development Studies, University of Sussex, UK.

UKCIP, 2015.Website of the UKCIP. UK Climate Impacts Programme (UKCIP). Available at: http://www.ukcip.org.uk/terms-conditions/\#.Vd2XTPIVhBc [accessed 26 August 2015].

UN, 2011. COP 17, Key statistics on Durban. Available at: http://www.cop17 cmp7durban.com/en/durban/about-durban.html [accessed 17 June 2015].

UNIDO, 2009. Climate change Mitigation of Industrial Activity through Investment and Technology Compacts and Partnerships- Durban, South Africa and China Work Plan. United Nations Industrial Development Organization. Available at:

https://www.unido.org/fileadmin/user media/UNIDO Worldwide/Offices/UNIDO Offi ces/South Africa/ClimatChangePartnershipSummary.pdf [accessed 26 August 2015].

UNISDR 2016 - Resilient Cities initiative, http://www.unisdr.org/campaign/resilientcities/ [accessed 26 February 2016].

UNISDR, 2015. Sendai Framework for Disaster Risk Reduction 2015-2030. The United Nations Office for Disaster Risk Reduction. Available at http://www.preventionweb.net/files/43291 sendaiframeworkfordrren.pdf [accessed 26 August 2015].

UNISDR, 2011. Hyogo Framework for Action 2005-2015 mid-term review. United Nations Office for Disaster Risk Reduction . Available at: http://www.unisdr.org/we/inform/publications/18197 [accessed 26 August 2015]. Vasconcellos, M., and Vasconcellos, A. M., 2009. Partnership, empowerment and local development. Interações (Campo Grande), 10(2), pp. 133-148.

Wohlstetter, P., Smith, J., and Malloy, C. L. (2005). Strategic alliances in action: Toward a theory of evolution. Policy Studies Journal, 33(3), pp. 419-442. 